\title{
BEAUTY QUEENS AND BATTLING KNIGHTS: RISK TAKING AND ATTRACTIVENESS IN CHESS*
}

\author{
ANNA DREBER ${ }^{\dagger}$ \\ CHRISTER GERDES ${ }^{\ddagger}$ \\ PATRIK GRÄNSMARK ${ }^{\S}$
}

\begin{abstract}
We explore the relationship between attractiveness and risk taking in chess. We use a large international panel dataset on chess competitions which includes a control for the players' skill in chess. This data is combined with results from a survey on an online labor market where participants were asked to rate the photos of 626 expert chess players according to attractiveness. Our results suggest that male chess players choose significantly riskier strategies when playing against an attractive female opponent, even though this does not improve their performance. Women's strategies are not affected by the attractiveness of the opponent.
\end{abstract}

Keywords: risk taking, attractiveness, chess, gender differences

Classification codes: D03, J16

\footnotetext{
* We are grateful for help with the survey software and MTurk from Lydia Chilton, Jason Poulos and David G. Rand, as well as comments from Johan Almenberg, Alison Cool, Emma von Essen, Bart Golsteyn, Moshe Hoffman, Magnus Johannesson, Robert Östling, David G. Rand, Eskil Wadensjö and participants at the SOFI seminar. A special thanks to the makers of ChessBase, who kindly allowed us to use their data.

${ }^{\dagger}$ Institute for Financial Research (SIFR). Anna.Dreber@sifr.org

‡ IZA, Swedish Institute for Social Research (SOFI). christer.gerdes@sofi.su.se

$\S$ Corresponding author. Swedish Institute for Social Research, Stockholm University, SE-10691 Stockholm, Sweden. patrik.gransmark@sofi.su.se
} 


\section{INTRODUCTION}

Risk preferences are typically studied from situations in which individuals make decisions in isolation. In many instances, however, one individual's risk taking has consequences on the outcome of another individual, as in the case of competitions where decisions involve risk. To what extent characteristics of one individual affect risk taking by another individual is relatively unexplored. In particular, little is known about the role of physical traits on risk taking. In this paper we focus on attractiveness. In practice, it can be hard to get reliable data on outcomes regarding risk and attractiveness. Options as well as outcomes are not always easily defined when decisions are made outside of the laboratory, and as Eckel and Wilson (2004) discuss, physical appearance could be used as a heuristic when people try to form an opinion about an unfamiliar individual's ability and characteristics. It can therefore be a challenge to disentangle attractiveness from for example beliefs about ability. We argue that the data used in this paper enables us to disentangle the specific effect of attractiveness on risk taking, by allowing us to study relevant outcome variables while controlling for aspects such as ability. Such information is publicly available, which means that the subjects studied in this study do not have to use attractiveness as a proxy for another individual's ability.

The goal of this paper is to explore the role of attractiveness in chess, by linking it to risk taking. In particular, we examine whether people use riskier strategies against attractive people, whether this affects performance, and whether men and women react to attractiveness in the same way. In order to test this, we use a large international panel dataset on chess tournaments which includes controls for the players' age, gender, nationality, risk taking/aggressiveness and playing strength, measured by cumulative performance. We use photos of some of these chess players and have them rated according to attractiveness by participants recruited through an online labor market. To increase the reliability of our findings, we use two independent measures of risk taking. The fact that they lead to very similar findings strengthens the results substantially.

Our results suggest that male chess players choose significantly riskier strategies the more attractive the female opponent they are playing against. Women, however, do not react to the attractiveness of their opponents. Moreover, riskier play against an attractive female opponent has no positive impact on performance, which implies that economic rationality is unlikely to be the reason for the increased risk taking against attractive female opponents. Finally, we find some weak indications of more attractive players of both sexes choosing more risky strategies than less attractive players. 
The chess data set, which contains information on international chess games performed by expert chess players, enables us to analyze strategic interactions between people with substantial experience in the task. These objective and observational data are combined with survey responses for 626 chess players who were subjectively rated for physical attractiveness. Each photo received about 50 independent ratings. Approximately half of the chess players of whom we have photos were women.

Using the same chess data as in this study, Gerdes and Gränsmark (2010) found that men use riskier strategies than women, and that this gap is especially large when men play against women. Part of our goal in this study is to further our understanding of the cause of these effects, that might also occur in other domains than chess. That men take more risk than women in general is a well-documented finding (see e.g. Croson and Gneezy 2009 or Eckel and Grossman 2008 for reviews of this literature), but as far as we know, the relationship between attractiveness and risk taking has not been studied before.

The contribution of this paper is thus two-fold. First, we contribute to the literature on the determinants of risk taking. Besides having the playing strength of both players, as well as demographic characteristics, the data allow us to include a measure of the stake of each game played. The tournaments are an environment which is highly competitive thus a priori we don't expect people to change their behavior due to characteristics of their opponents which are not relevant for the game. Thus we believe that the effect size of attractiveness on the behavior of male players provide us with a lower bound of how attractiveness affects male risk taking in general.

Second, we contribute to the growing literature on the role of attractiveness for decision making and economic outcomes. The positive correlation between physical attractiveness and wages, as well as other labor market outcomes, is a well-established result in the social and economic literature (Hamermesh and Biddle 1994, Biddle and Hamermesh 1998). ${ }^{1}$ As Fletcher (2008) notes, the reasons for a "beauty premium” in the labor market are largely unknown, as it might be caused by various forms of discrimination (either by employers or customers), or by self-selection to occupations where there is a higher reward for physical attractiveness. In addition, it has been found that more attractive people have better verbal skills, which could be useful when searching/negotiating for a job or for school performance (Mobius and Rosenblatt 2006). Experiments on social preferences have also shown that physically attractive people are seen to be more cooperative in the public goods

\footnotetext{
${ }^{1}$ Beauty has also been related to electoral success (e.g., Berggren et al. 2010).
} 
game (Andreoni and Petrie 2008), are given higher offers in the ultimatum game but are also demanded of more (Solnick and Schweitzer 1999), and are trusted more in the trust game (Wilson and Eckel 2006) than less attractive people. Combined, these results suggest that physical appearance could impact social stratification and the distribution of opportunities. ${ }^{2}$

There are also previous examples of how the attractiveness of others affects men's and women's decision making differently. For example, Wilson and Daly (2004) show that men become more impatient when seeing an attractive woman than when seeing a less attractive woman, whereas women's behavior is not affected by whether a male is attractive or not. ${ }^{3}$ In a field experiment on door-to-door charitable fundraising, Landry et al. (2006) find that male charitable donor prospects respond more than female prospects to female solicitor attractiveness. In another field experiment where mail with varying content (advertising content, loan price and loan offer deadlines) is sent out to former clients of a large consumer lender, Bertrand et al. (2010) find that when seeing the photo of an attractive woman in the ad, male clients take up significantly more loans whereas women do not react to the attractive woman nor to an attractive man. The effect for male borrowers is substantial: the presence of the female photo increases loan demand similarly to a 25 percent decrease in the interest rate.

When considering attractiveness in the labor market, for instance at a job interview, it could be used as a proxy for health. An unhealthy individual may very well look less attractive and a lower degree of attractiveness could therefore indicate lower productivity. Thus, when an employer chooses an attractive job applicant it does not have to be due to the fact that the applicant is attractive but rather because he or she signals a high level of health and productivity. The most obvious advantage with using chess data is the Elo rating which is a recurrently updated objective measure of a player's chess skill. ${ }^{4}$ Thus the fact that attractiveness may signal health status is not a problem here. ${ }^{5}$

\footnotetext{
${ }^{2}$ See also Mulford et al. (1998, p. 1587) for similar findings.

${ }^{3}$ Daly and Wilson (2004) suggest that this gender difference could be due to the fact that men but not women found attractive photos to be arousing and that this arousal activated neural mechanisms associated with cues of mating opportunity. Another study focusing on time preferences and sexual cues among men only suggests that it is not about mating opportunity per se but rather about the role of an activated general reward circuitry (Van den Bergh et al. 2008). ${ }^{4}$ See “Arpad Elo and the Elo Rating System” by Daniel Ross for a more detailed discussion on the Elo rating.

${ }^{4}$ See “Arpad Elo and the Elo Rating System” by Daniel Ross for a more detailed discussion on the Elo rating.

${ }^{5}$ It could be the case that people use attractiveness as some type of heuristic for how their opponent will play. However, this does not explain why attractiveness only matters for how male players play against women.
} 
Our paper is organized as follows. The next section discusses the data and statistics and Section 3 presents the conceptual framework. Section 4 presents the results of the estimations and Section 5 concludes and discusses promising directions for future research.

\section{DATA}

In this study we exploit two datasets: an observational dataset from international expert chess games stretching over a period of 11 years with approximately 100,000 games, and a dataset resulting from 61 online surveys with approximately 2,000 participants.

The observational data were obtained from ChessBase 10 which is a database collection for chess players. For each player there is information available on their name, year of birth, nationality and gender. For every game there are data on the names and Elo-ratings of the two players (where Elo ratings indicate playing strength), year when the game was played, number of moves and the score, i.e. the outcome of a game in terms of a win, loss or draw. In this study we include games played between 1997 and 2007 where the minimum Elo-rating for each included player is set to 2000, above which players are considered to be experts. The measures of risk taking are explained in detail in the next section. The players come from 140 countries though most originate in Europe or in the former Soviet Union (see Section 4). Due to the fact that the data contain information on both the player in focus and the opponent it is possible to study the specific interaction of these two players as well as all other games each player has played or plays subsequently. The panel data structure allows us to control for individual fixed effects which account for time constant differences.

The online survey was carried out through the crowdsourcing web service Amazon Mechanical Turk (MTurk) where participants log on to an internet account to do tasks that require human intelligence to complete (a task on MTurk is called a "HIT", which stands for Human Intelligence Task) for which they receive small payments. In our case, participants could voluntarily agree to fill out surveys for which they were paid $\$ 0.50$ for each survey. ${ }^{6}$ One individual was allowed to participate in several different surveys, but only to rate a given photo once. Each survey contained ten to twelve photos, and the survey was assumed to take about eight minutes to fill out. In practice, the average time spent filling out the survey was five to six minutes. All data were collected during one week in September of 2010. The participants were required to have a HIT approval rate greater than or equal to 95 percent

\footnotetext{
${ }^{6}$ See Horton et al. (2010) and Paolacci et al. (2010) and references therein for research on MTurk surveys. Note also that the typical worker on MTurk is willing to work for about \$1.40 per hour (Horton and Chilton in press).
} 
(which implies that at least 95\% of their previous HITs were to the satisfaction of their employer) as well as to be in the US. It has previously been shown that the population on MTurk is at least as representative of the US population as traditional subject pools (Buhrmester et al. in press, Paolacci et al. 2010).

In each survey, half of the photos were of male chess players and half of female players. ${ }^{7}$ The order in which these photos were presented to each rater was randomized. We use an 11-point scale ranging from 0 (Not at all attractive) to 10 (Very attractive). ${ }^{8}$ Participants were asked to give a rating for each photo on this scale. Each photo was rated about 50 times. We also asked the participants for their gender, age, nationality, education and labor force situation. See the Appendix for some descriptives on the raters. On average about 60 percent of the raters were women, and the average age was 35.

As photos were not available for all players in the dataset we selected a subgroup of the total population. We call this subgroup the MTurk sample. The photos used in the survey were chosen for players who were between 25 and 34 years old in the year 2010. The photos sampled were taken between 1997 and 2007, and most of them are headshots. There were more male players with photos available than female players so we selected all female players between the age of 25 and 34 with photos as well as all male players from every third year within that range who had photos. This resulted in approximately the same number of female and male photos.

\section{CONCEPTUAL FRAMEWORK}

To measure risk behavior we use two independent approaches which we believe are good proxies for economic risk, where risk aversion implies choosing the safer alternative rather then gambling for the same expected payoff. The first measure builds on the choice of chess opening strategy where the players can choose between a risky, neutral or safe strategy. The second measure exploits the existence of draws in chess as a draw gives half a point with certainty rather than gambling for a win with the risk of losing.

There are three possible results in chess: a win, a draw and a loss which gives one point, half a point and zero points respectively. When a chess game starts it is in a "saddle point equilibrium”, i.e. a draw with half a point for each player. When two equally strong players

\footnotetext{
${ }^{7}$ It is unlikely that the raters recognized any of the chess players they rated, since even though some of these players might be well known in the chess world, they are typically unknown outside of their field.

${ }^{8}$ We ask the participants the following question: "Physical attractiveness: How physically attractive do you find this person, on a scale from 0 to 10 where 0 is "Not at all attractive" and 10 is "Very attractive"?".
} 
meet, the probability for a draw is higher than in cases when the players are of different playing strength. To increase the winning probability a player must accept a higher level of risk which reduces the drawing probability and increases the winning/losing probabilities. Figure 1 shows two examples of opening choices where the first example is more risky as it leads to a smaller drawing probability and higher winning/losing probabilities. The second example is a more risk averse choice as the drawing probability is greater.

Figure 1 - Outcome probabilities for wins, draws and losses (from white perspective) for two opening strategies based on real game data (a Sicilian defence where the starting moves 1.e4c5 have been played). ${ }^{9}$

2.d4 - the risky Morra gambit

\begin{tabular}{|c|c|c|}
\hline $34.7 \%$ & $20.1 \%$ & $45.3 \%$ \\
\hline \multicolumn{3}{|c|}{ 2.c3 - the safer Alapin variation } \\
\hline $32 \%$ & $34.7 \%$ & $33.3 \%$ \\
\hline
\end{tabular}

In chess, the term aggressive play is used when indicating a strategy that reduces the drawing probability while the term solid play is used to indicate a strategy that reduces the winning/losing probabilities.

\section{Risk as measured by the choice of opening strategy}

At the beginning of a chess game, both players choose an opening strategy (a strategic development scheme for their pieces) that will steer the game towards a style of play that best suits him or her at the same time as they try to make the style of play less comfortable for the opponent. All expert chess players have a prepared set of opening strategies to be used in different situations. One's chosen set of openings is called an "opening repertoire” (OR). To optimize performance, considerable effort is dedicated to create an opening repertoire that matches one's personality.

A risky opening strategy involves a higher level of risk, as launching an attack on one part of the board implies that you neglect another. Typically, in such positions every move

9 The percentages and images taken from
http://www.chessgames.com/perl/explorer?node=32033\&move=2\&moves=e4.c5\&nodes=21720.32033 
tends to be of utmost importance where one small mistake can alter the balance of the game in favor of the opponent. Risk averse strategies avoid many possible weaknesses but at the cost of fewer attacking possibilities. Usually, one slip in a solid position will not lose the game.

The opening moves are "theoretical" and are memorized before the game, and, since no calculation is needed, these moves are played quickly. For each move, the opening theory covers the most reasonable moves by the opponent (typically 15-20 moves in depth). ${ }^{10}$ The definition of chess opening theory implies that the game remains in the saddle point equilibrium during the opening moves. This means that as long as both players keep playing theoretical moves, there is no advantage for either side. For instance, if the theory of a certain opening variation lasts for twenty moves then the "real" play and a potential deviation from the saddle point equilibrium does not start until the $21^{\text {st }}$ move.

In a game theoretical framework chess is a sequential game where the players make moves in turn. Figure 2 shows an opening to exemplify the grounds on which it is considered as risky or safe.

Figure 2 - A game tree displaying risky and safe opening choices in chess.

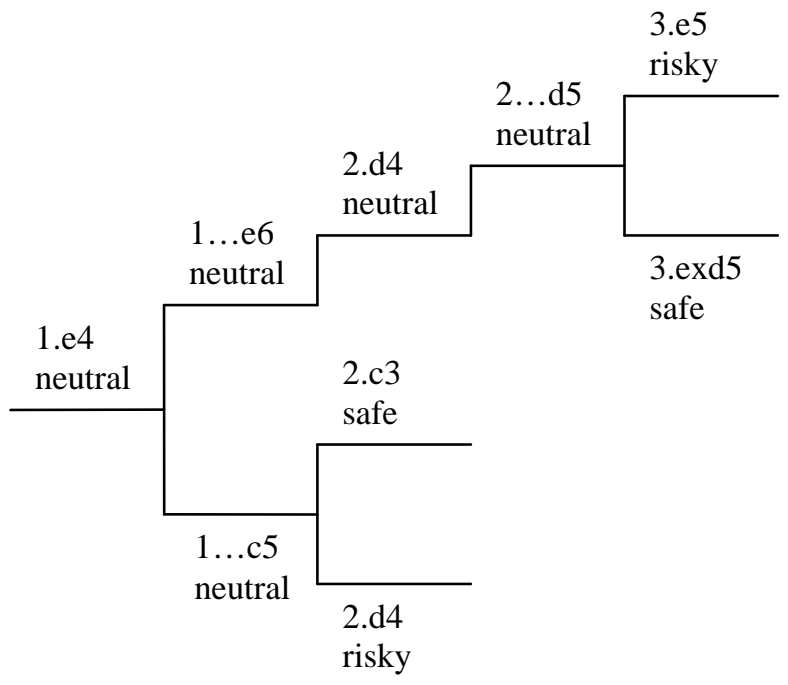

After the first move for each side (1.e4 and 1...e6/1...c5), it is too early to classify the opening as being safe or risky. ${ }^{11}$ In the first end-node of the game tree, white grabs space with

\footnotetext{
${ }^{10}$ See Batsford's Modern Chess Openings (2005).

11 To ease notation, the game tree only shows the possible strategies from the perspective of the player of the white pieces. Also, for the sake of simplicity, only pawn moves are discussed here. The annotation "1...e6"
} 
3.e5, which will be used for an attack later on. In the second end-node, 3.exd5, white chooses a symmetric position without space advantage but avoiding weaknesses. In the third endnode, 2.c3, white chooses a safer system, but in the fourth, 2.d4, a pawn is sacrificed to assure initiative and attack. If the pawn sacrifice does not result in a tangible advantage the opponent will eventually have greater winning probabilities than when the game started.

There is a standardized classification of opening strategies, called the ECO codes. To create a risk measure, our aim is to be able to label each of the 500 openings as being either risky, neutral or safe. To obtain the labels for each opening we consulted eight chess experts of different skills with Elo rates ranging from 2000 to 2600, five men and three women, and asked them to give their opinion on the character of all the 500 Eco codes. ${ }^{12}$ In more detail, they were instructed to define each opening as either risky, neutral or safe. We then compare the opinions of the experts and declare an Eco code to be risky, neutral or safe if at least six out of eight experts define it as either risky or safe. ${ }^{13}$ In cases when there are five or fewer votes for either risky or safe, the opening is considered to be neutral. As a result of our experts' assessments, there are two labels for each game, one for the player of the white pieces and one for the black, i.e. one player may try to give the game a risky character while the other may try to keep it safe.

\section{Risk as measured by preferences for a draw}

A draw can be offered by a player and accepted or rejected by the opponent at any time during the game. Such an outcome alternative in real world games is very rare and the fact that it exists in chess makes the game suitable for studying risk behavior. There are no rules regulating the minimum number of moves that have to be played before the players can agree upon a draw except that the game must have started. We argue that, when controlling for differences in playing strength, two risk averse players have higher preferences for a draw

should be understood as: "the first move (1.) for black (...) and a pawn is moved to the coordinate e6.” In "exd5” $\mathrm{x}$ reads as "takes on."

12 According to the International Chess Federation (FIDE), a player is regarded as an expert if he/she has an Elo rating of 2000 or more. The lowest level required to obtain a Master title is a rating of 2300. A Grandmaster title usually implies an Elo rating of over 2500. In the year 1999 Garry Kasparov reached an Elo rating of 2851, the highest Elo rating ever measured.

${ }^{13}$ The reason for creating a binary (or actually “trinary”) variable and not a “continuous” variable ranging from 0 to 10 is that the classification requires a very high level of expertise from the participating judges. Each of the judges needed several hours to complete the survey on the 500 opening codes and asking them to classify the openings on a broader scale would be unreasonable. Future work could explore this further. 
than two risk loving players as a draw gives half a point with certainty rather than playing for a win of one point with the risk of losing and getting zero points. For each additional move that is played in a game there is a risk for deviation from the saddle point equilibrium with a reduced probability for a draw. Expressed differently, if two equally skilled players have risk averse preferences they would reduce the risk by agreeing to a draw at an early stage. If one of two equally skilled players have made a mistake on the board the probability of a draw is lower than when the position is still in the saddle point equilibrium. Draws agreed to while still in the saddle point equilibrium are usually referred to as "arranged draws". Since the players have not really started to play, arranged draws depend on the players' preferences, while draws agreed to at a later stage, when the theory has ended, depends increasingly on the position on the chess board for each additional move. Thus, an arranged draw reflects the risk behavior a priori.

By studying the probability for a draw compared to the probability of playing for a win with the risk of losing we obtain a measure of the drawing preferences. As has been argued above, risk averse players have higher preferences for draws while risk loving players prefer to play for a win. This proxy of risk behavior is likely to be stronger the earlier in the game the draw has been agreed to. For this reason we compare games ended in a draw with games ended in wins/losses for different game lengths in moves.

Recapitulating, the first measure of risk is based on the choice of opening strategy which we quantified with the help of a small scale survey among eight expert chess players where 500 different opening strategies were classified as either risk averse, risk neutral or risk loving. The second measure is obtained by studying the preferences for agreeing to a draw. As this proxy measures the probability for choosing the expected payoff with certainty rather than gambling for a win with the risk of losing, we mean that it is a reasonable proxy for risk preferences.

When it comes to the empirical framework, the questions addressed in this paper require different econometric models. All models estimated are using OLS. We look at three types of outcome variables: the type of opening (risky or non-risky), the performance of a chosen strategy, and whether the outcome is a draw. When testing for the propensity of choosing an aggressive opening, the outcome variable is a binary dependent variable (coded as one or zero). When testing the performance of a chosen strategy we include all three possible outcomes in chess, which are a win (1 point), a draw ( $1 \frac{1}{2}$ point) and a loss ( 0 point). When testing for the propensity of the outcome being a draw, the outcome variable is binary (coded as one or zero). The coefficients from the binary models are interpreted as the 
marginal probability for the outcome to occur. For the "trinary" outcome variable on performance, on the other hand, the coefficients are interpreted as the marginal gain in terms of so called "score points" as will be explained below.

In the first set of regression estimations we look at how players in the MTurk-sample choose opening strategies, i.e. we look at the role of attractiveness for choosing an aggressive opening strategy, as well as the relationship between the level of attractiveness and the score points for a game. Subsequently, which is the focus of our analysis, we look at the behavior of chess players when playing against an opponent within the MTurk-sample. In the latter set of estimations we can control for aspects such as individual heterogeneity as well as differences in both opponents' chess productivity. We thereafter explore the determinants of the outcome being a draw or not, testing whether this is affected by the attractiveness of the opponent.

\section{RESULTS}

\section{Descriptive statistics}

Table 1 shows summary statistics for the players that have been rated for their physical attractiveness. By design of the survey about half the players are women, and the age distribution is rather similar across gender. The share of male players from Western Europe is about 50 percent, while the corresponding number for female players is 30 percent. The share of players from Eastern Europe and the former Soviet Union is about 50 percent for women and 25 for men. As for the rating on physical attractiveness, women are somewhat higher rated than the male players, but the difference is not significant. In Table A.0 in Appendix, we run regression estimations to see if it matters whether the rater is a woman or a man. In general, female raters are giving ratings that are 1.3 point higher than those of male raters, see column (1). The coefficient regarding the interaction of being a female rater and the sex of the rated player turns out to be insignificant, saying that female raters do not rate photos with female players differently than what male raters do. 
Table 1 - Mean values at the individual level for the MTurk-sample.

\begin{tabular}{|c|c|c|c|c|c|c|}
\hline \multirow[b]{2}{*}{ Variable } & \multicolumn{2}{|c|}{ All } & \multicolumn{2}{|c|}{ Men } & \multicolumn{2}{|c|}{ Women } \\
\hline & Mean & Std. Dev. & Mean & Std. Dev. & Mean & Std. Dev. \\
\hline Risk averse OR & 0.439 & & 0.441 & & 0.438 & \\
\hline Risk loving OR & 0.222 & & 0.234 & & 0.210 & \\
\hline Female & 0.498 & & 0 & & 1 & \\
\hline Attractiveness & 6.077 & $(1.078)$ & 5.775 & $(.936)$ & 6.381 & $(1.126)$ \\
\hline Elo & 2247.566 & $(142.665)$ & 2302.921 & $(143.174)$ & 2191.857 & (118.597) \\
\hline Age & 21.998 & $(2.777)$ & 22.465 & $(2.583)$ & 21.529 & $(2.888)$ \\
\hline \multicolumn{7}{|l|}{ Number of games } \\
\hline played per year & 26.003 & $(20.005)$ & 27.829 & $(22.304)$ & 24.165 & $(17.228)$ \\
\hline North America & 0.030 & & 0.035 & & 0.026 & \\
\hline Latin America & 0.056 & & 0.038 & & 0.074 & \\
\hline Nordic countries & 0.042 & & 0.048 & & 0.035 & \\
\hline Western Europe* & 0.358 & & 0.471 & & 0.244 & \\
\hline Eastern Europe & 0.200 & & 0.140 & & 0.260 & \\
\hline fr Soviet Union & 0.181 & & 0.108 & & 0.253 & \\
\hline \multicolumn{7}{|l|}{ N Africa /Mid } \\
\hline East & 0.026 & & 0.029 & & 0.022 & \\
\hline East Asia & 0.083 & & 0.086 & & 0.080 & \\
\hline Africa & 0.003 & & 0.003 & & 0.003 & \\
\hline Number of players & 626 & & 314 & & 312 & \\
\hline
\end{tabular}

Note: All mean values calculated on figures according to the period 1997 to 2007. * Net of Nordic countries.

\section{Estimation results: MTurk-sample only}

Table 2 and Table 3 show regression estimations where playing an aggressive opening is the dependent variable, for male and female players respectively. Only players from the MTurksample are included. The aim is to look at the marginal importance of degree of attractiveness for ones choice of risky openings. Subsequently, a number of control variables are added to the estimations: opponent playing risk averse strategy Elo points at stake and Elo point differences. The first control variable addresses the fact that women choose risk averse openings to a greater extent than men (as shown in Table A1 in the Appendix), which per se might trigger a player to respond by playing a more risky strategy. The second control 
variable picks up the marginal amount of Elo points a player can gain by winning that game. Lastly, differences in Elo points are meant to hold constant the statistical chances of winning. As seen below, the regression coefficients regarding Attractiveness are rather stable across the different models estimated. These results point to a positive correlation, though not significant, between physical attractiveness and the propensity of choosing a risky opening irrespective of gender. The impact seems more robust and slightly larger for male players. Notice that figures in column (4) in Table 2 and Table 3 report estimations where the control for Elo has been removed, just to test for the sensitivity of coefficients with respect to such controls. As it turns out, this does not cause any differences in the results. ${ }^{14}$

\footnotetext{
${ }^{14}$ To see how attractive players perform when playing riskier strategies, we also run a regression with performance (score) as the outcome variable. The results are presented in Table A2 and A3 in appendix. The coefficient estimates suggest that there is no significant correlation between a player's physical attractiveness and his/her performance.
} 
Table 2 - OLS estimations regarding the impact of physical attractiveness and playing against a woman on the choice of opening strategy for the players in the MTurk-sample. MEN.

Dependent variable: Choosing risky opening strategies, yes (1) or no (0)

(1)

(2)

(3)

(4)

No Elo

\begin{tabular}{lcccc} 
& & & & No Elo \\
Attractiveness & $\mathbf{0 . 0 1 0 1}$ & $\mathbf{0 . 0 1 0 3}$ & $\mathbf{0 . 0 1 0 3}$ & control \\
& $\mathbf{( 0 . 0 0 7 1 )}$ & $\mathbf{( 0 . 0 0 6 5 )}$ & $\mathbf{( 0 . 0 0 6 5 )}$ & $\mathbf{( 0 . 0 0 6 5 )}$ \\
Female opponent & & 0.0111 & 0.0139 & 0.0131 \\
& & $(0.0091)$ & $(0.0091)$ & $(0.0094)$ \\
Individual fixed effects & No & No & No & No \\
Opponent playing risk averse & No & Yes & Yes & Yes \\
strategy & & & & No \\
Elo points at stake & No & No & Yes & No \\
Elo differences & No & No & Yes & 59004 \\
Observations & 59004 & 59004 & 59004 & 314 \\
Number of players & 314 & 314 & 314 & \\
\hline
\end{tabular}

Note: Robust standard errors in parentheses, clustered at player level. Other control variables are Elo, age, age squared, age_max_20, log (number of games played), year dummies. Sample not restricted with respect to number of games played. * significant at $10 \%$; ** significant at $5 \%$; *** significant at $1 \%$ 
Table 3 - OLS estimations regarding the impact of physical attractiveness and playing against a woman on the choice of opening strategy for the players in the MTurk-sample. WOMEN.

Dependent variable: Choosing risky opening strategies, yes (1) or no (0)

(1)

(2)

(3)

(4)

No Elo

control

$\begin{array}{lcccc}\text { Attractiveness } & 0.0061 & 0.0066 & 0.0067 & 0.0070 \\ & (0.0083) & (0.0076) & (0.0076) & \mathbf{( 0 . 0 0 7 6 )}\end{array}$

Female opponent

$-0.0076$

$-0.0089$

$-0.0099$

(0.0063)

(0.0064)

(0.0068)

Individual fixed effects

No

No

No

No

No

Opponent playing risk averse

Yes

Yes

Yes

strategy

Elo points at stake

No

Elo differences

No

No

Yes

Yes

No

Observations

48234

No

48234

48234

312

312

Note: Robust standard errors in parentheses, clustered at player level. Other control variables are Elo, age, age squared, age_max_20, log (number of games played), year dummies. Sample not restricted with respect to number of games played. * significant at $10 \%$; ** significant at $5 \%$; *** significant at $1 \%$

\section{Estimation results: the importance of meeting an attractive opponent}

So far we have been studying how the players in the MTurk-sample choose opening strategies. Next, we look at how other players interact with the MTurk-sample, i.e. we analyze what strategies other players choose when they meet players from the MTurk-sample. We focus especially on the physical attractiveness ratings of the MTurk-players.

Summary statistics for the sample used in the regression estimations are shown in Table 4. In this section only games where the opponent is one of the 626 players in the MTurk-sample are included. The variable "Result", already used in the estimations above, indicates the score that is achieved in a chess game. A chess game can result in a win, draw, or loss, which gives $1,0.5$, or 0 points respectively. The average outcome should be 0.5 if both players in each game would be included in the sample. Here the mean values do not sum up exactly to 0.5 , which is due to the fact that in the estimations we have conditioned on the 
player (but not his or her opponent) having a record of more than 20 games over the total time period studied. As some of the opponents in the MTurk sample do not fulfill this condition, the aggregated scores do not sum up to 0.5. Below we will use the score of a game in estimations where we test for the rationality of playing risky openings.

Table 4 - Mean values at game level for the sample used in the estimations.

\begin{tabular}{|c|c|c|c|c|c|c|}
\hline \multirow[b]{2}{*}{ Variable } & \multicolumn{2}{|c|}{ All } & \multicolumn{2}{|c|}{ Men } & \multicolumn{2}{|c|}{ Women } \\
\hline & Mean & Std. Dev. & Mean & Std. Dev. & Mean & Std. Dev. \\
\hline Risk-averse OR & 0.462 & & 0.465 & & 0.457 & \\
\hline Risk loving OR & 0.214 & & 0.216 & & 0.211 & \\
\hline Elo score & 2355.843 & (159.440) & 2397.266 & $(153.681)$ & 2261.123 & $(129.032)$ \\
\hline Age & 29.251 & (11.503) & 31.250 & (11.895) & 24.679 & (9.018) \\
\hline \multicolumn{7}{|l|}{ Aged max 20 in } \\
\hline$\%$ & 0.285 & & 0.220 & & 0.435 & \\
\hline \multicolumn{7}{|l|}{ Number of games } \\
\hline played per year & 39.544 & (29.954) & 41.457 & $(32.245)$ & 35.171 & (23.323) \\
\hline North America & 0.030 & & 0.034 & & 0.019 & \\
\hline Latin America & 0.037 & & 0.043 & & 0.022 & \\
\hline Nordic countries & 0.050 & & 0.061 & & 0.025 & \\
\hline Western Europe* & 0.321 & & 0.370 & & 0.211 & \\
\hline Eastern Europe & 0.259 & & 0.235 & & 0.315 & \\
\hline fr Soviet Union & 0.234 & & 0.189 & & 0.337 & \\
\hline \multicolumn{7}{|l|}{ N Africa /Mid } \\
\hline East & 0.018 & & 0.018 & & 0.016 & \\
\hline East Asia & 0.042 & & 0.038 & & 0.053 & \\
\hline Africa & 0.001 & & 0.001 & & 0.001 & \\
\hline Result & 0.476 & $(0.397)$ & 0.484 & $(0.395)$ & 0.458 & $(0.402)$ \\
\hline Number of games & 101024 & & 70286 & & 30738 & \\
\hline Number of players & 11107 & & 9848 & & 1259 & \\
\hline
\end{tabular}

Note: All mean values calculated on figures according to the period 1997 to 2007. * Net of Nordic countries. Observations for those included in regression estimations. Sample with 20 or more games played during the period studied. 
In Table 5 and Table 6 below we explore the importance of the opponent's gender as well as his or her physical attractiveness in the estimations. Column (1) in Table 5 and Table 6 shows how male/female players are choosing openings when meeting one of the players in the MTurk-sample. The focus here is on the marginal impact of meeting a female opponent. The coefficient estimate on playing against a female is insignificant for both men and women. In column (2) the measure of the opponent's physical attractiveness is added to the model, which only has a minor impact on the female opponent variable. Things change significantly, however, once we include an interaction term of the gender of the opponent and his or her rating of physical attractiveness, at least when it comes to the behavior of male players, as shown in column (3) in Table 5. There is thus evidence that playing against a more attractive female player leads to a larger propensity of choosing aggressive openings if the player is a man. For female players, on the other hand, the behavior does not show sensitivity to such aspects, see column (3) in Table 6. Here one should notice that women play against other female players far more often than what men do, i.e. female players meet one player of the same sex in about 94 of 100 games, while the corresponding figure for male players is ca 77 out of 100 games. $^{15}$ In column (4) in both tables we show estimations where we do not control for individual fixed effects. The estimates change slightly, and the coefficient for the impact of playing against attractive female opponents becomes smaller. The interaction effect of playing aggressively against a female opponent is determined by two aspects: the coefficient on female opponent and the coefficient on attractiveness and female opponent. Thus, according to column (3) in Table 5 the interaction effect reads -0.0765+attractiveness rate of the female opponent*0.0123. Using the mean value of attractiveness for the female sample, which is 6.57, the average effect becomes 0.0043. In case we use the top (lower) decile on the attractiveness rating for female players which is 8.0 (5.02), the effect becomes

\footnotetext{
${ }^{15}$ These numbers have to be interpreted with caution. By design there are about equally many women as men in the MTurk-sample. As we condition on playing against one of the players in that sample, the share of games against an opponent of the same sex is pushed upwards (downwards) for women (men). There are two types of tournaments in chess: mixed and all-female. This means that female players have access to a greater variety of tournaments than male players. It could be the case that women condition on the degree of competitive play when choosing tournaments, i.e. some women might choose tournaments where they mostly meet other (risk averse) female players. This would imply that those women competing in tournaments where they meet male players are relatively more competitive than other female players. To what extent this has an impact on the found non-significance of conditioning risky play against more attractive female opponents is not clear.
} 
0.0219 (-0.0148). ${ }^{16}$ From Table 4 we see that on average male players chose a risky opening in 21.4 percent of all games. When comparing that value with our found estimate of playing against a female opponent in the top decile of the MTurk-sample of female players in terms of attractiveness, there is thus a marginal increase of about 10 percent.

Table 5 - OLS estimations regarding the impact of playing against a woman on the choice of opening when controlling for the opponent's physical attractiveness. MEN.

Dependent variable: Choosing risky opening strategies, yes (1) or no (0)

\section{(1)}

(2)

(3)

(4)

No fixed

effects

Female opponent

0.0016

(0.0047)

Attractiveness of opponent

Attractiveness and female

opponent

Individual fixed effects

Opponent playing risk averse

strategy

Elo points at stake

Elo differences

Observations

Number of players
Yes

Yes

Yes

Yes

70286

9848

0.0014

(0.0049)

0.0003

(0.0018)

$(0.0018)$ age squared, age_max_20, log (number of games played), year dummies. Sample with 20 or more games played during the period studied. * significant at $10 \%$; ** significant at $5 \%$; *** significant at $1 \%$

\footnotetext{
${ }^{16}$ By the setup of the model we measure the average interaction effect. In general there could be non-linear patterns in the way female attractiveness affect playing style, an aspect we leave for future research.
} 
Table 6 - OLS estimations regarding the impact of playing against a woman on the choice of opening when controlling for the opponent's physical attractiveness. WOMEN.

Dependent variable: Choosing risky opening strategies, yes (1) or no (0)

\begin{tabular}{lcccc}
\hline & $(1)$ & $(2)$ & $(3)$ & $\begin{array}{c}\text { No fixed } \\
\text { effects }\end{array}$ \\
Female opponent & & & & $\mathbf{0 . 0 1 5 3}$ \\
& $\mathbf{- 0 . 0 0 7 5}$ & $\mathbf{- 0 . 0 0 8 6}$ & $\mathbf{- 0 . 0 1 5 5}$ & $\mathbf{( 0 . 0 6 1 5 )}$ \\
Attractiveness of opponent & $\mathbf{( 0 . 0 1 0 6 )}$ & $\mathbf{( 0 . 0 1 0 8 )}$ & $\mathbf{( 0 . 0 6 0 7 )}$ & 0.0012 \\
& & 0.0013 & 0.0002 & $\mathbf{0 . 0 1 0 3 )}$ \\
Attractiveness and female & & $(0.0022)$ & $(0.0101)$ & $\mathbf{- 0 . 0 0 2 7}$ \\
opponent & & & $\mathbf{0 . 0 0 1 2}$ & $\mathbf{( 0 . 0 1 0 5 )}$ \\
Individual fixed effects & & & $\mathbf{( 0 . 0 1 0 3 )}$ & No \\
Opponent playing risk averse & Yes & Yes & Yes & Yes \\
strategy & & & & Yes \\
Elo points at stake & Yes & Yes & Yes & Yes \\
Elo differences & Yes & Yes & Yes & 30 738 \\
Observations & 30 738 & 30738 & 30738 & 1259 \\
Number of players & 1259 & 1259 & 1259 & \\
\hline
\end{tabular}

Note: Robust standard errors in parentheses, clustered at player level. Other control variables are Elo, age, age squared, age_max_20, log (number of games played), year dummies. Sample with 20 or more games played during the period studied. * significant at $10 \%$; ** significant at $5 \%$; *** significant at $1 \%$

As we saw above, for men there is a higher propensity of choosing aggressive openings when playing against more attractive female opponents. One could argue that such behavior could be rational if it would lead to positive outcomes in terms of performance. In Table 7 and 8 we scrutinize this issue. For that purpose we look at the score points gained in each game, where a win, draw, or loss, results in $1,0.5$, or 0 points respectively. The model includes a number of interaction terms to catch all kind of cross-mechanisms that are related to the gender and attractiveness of the opponent. The interaction variable of main interest is the one marked in bold type, which states the marginal impact of playing aggressive openings against a female opponent, interacted by the level of her physical attractiveness. The estimates are not significant, but the overall trend is rather stable, suggesting that if anything, that 
playing a risky opening against more attractive female opponents comes with a cost. Thus, combining the results from Table 5 with those in Table 7 show that the behavior of men cannot be regarded as rational.

For women, we also see that there is a no benefit to play more aggressively against more attractive female opponents, see Table 8. However, as women do not seem to condition their choice of opening on the attractiveness of their opponent (as we saw in Table 6) there is no evident irrationality in their play. Excluding individual fixed-effects (see column 4 in Table 7 and Table 8) to some extent changes the estimates of interest. This suggests that heterogeneity across individuals with respect to time-constant aspects (for example cultural background) might be of some importance for the associations found here. ${ }^{17}$

\footnotetext{
${ }^{17}$ When using individual fixed effects the coefficient estimates are identified only by changes in the variables over all games played by each player. In other words, in such estimations a game played by two players has different impact for the estimations as each of the players has a different personal record of games over time. When we do not control for individual fixed effects, however, each game counts as (two) self-contained observations, which will force the performance outcome to its mean value of 0.5 . The latter point might explain some of the downward bias of the coefficient estimates in column (4) compared with column (3).
} 
Table 7 - OLS estimations regarding the probability of scoring when using a risky strategy against female opponents. MEN.

Dependent variable: The score achieved in a game

\begin{tabular}{|c|c|c|c|c|}
\hline & (1) & (2) & (3) & $\begin{array}{l}\text { no fixed } \\
\text { effects } \\
\text { (4) }\end{array}$ \\
\hline Playing risky & $\begin{array}{l}-0.0440 \\
(0.0276)\end{array}$ & $\begin{array}{l}-0.0171 \\
(0.0263)\end{array}$ & $\begin{array}{l}-0.0152 \\
(0.0259)\end{array}$ & $\begin{array}{l}-0.0187 \\
(0.0226)\end{array}$ \\
\hline Female opponent & $\begin{array}{c}0.2696 \\
(0.0280)^{* * *}\end{array}$ & $\begin{array}{c}0.0931 \\
(0.0270)^{* * *}\end{array}$ & $\begin{array}{c}0.0601 \\
(0.0265)^{* *}\end{array}$ & $\begin{array}{c}0.0556 \\
(0.0225)^{* *}\end{array}$ \\
\hline $\begin{array}{l}\text { Play risky against female } \\
\text { opponent }\end{array}$ & $\begin{array}{c}0.1168 \\
(0.0613)^{*}\end{array}$ & $\begin{array}{c}0.0638 \\
(0.0591)\end{array}$ & $\begin{array}{c}0.0430 \\
(0.0584)\end{array}$ & $\begin{array}{c}0.0252 \\
(0.0494)\end{array}$ \\
\hline Opponent's attractiveness & $\begin{array}{c}0.0042 \\
(0.0023)^{*}\end{array}$ & $\begin{array}{c}0.0013 \\
(0.0022)\end{array}$ & $\begin{array}{c}0.0010 \\
(0.0021)\end{array}$ & $\begin{array}{c}0.0018 \\
(0.0018)\end{array}$ \\
\hline $\begin{array}{l}\text { Attractiveness and female } \\
\text { opponent }\end{array}$ & $\begin{array}{c}-0.0176 \\
(0.0044)^{* * *}\end{array}$ & $\begin{array}{l}-0.0045 \\
(0.0042)\end{array}$ & $\begin{array}{l}-0.0035 \\
(0.0041)\end{array}$ & $\begin{array}{l}-0.0034 \\
(0.0035)\end{array}$ \\
\hline $\begin{array}{l}\text { Play risky and opponent's } \\
\text { attractiveness }\end{array}$ & $\begin{array}{c}0.0068 \\
(0.0048)\end{array}$ & $\begin{array}{c}0.0022 \\
(0.0045)\end{array}$ & $\begin{array}{c}0.0017 \\
(0.0045)\end{array}$ & $\begin{array}{c}0.0023 \\
(0.0039)\end{array}$ \\
\hline $\begin{array}{l}\text { Play risky against female } \\
\text { opponent and opponent's } \\
\text { attractiveness }\end{array}$ & $\begin{array}{c}-0.0192 \\
(0.0095)^{* *}\end{array}$ & $\begin{array}{l}-0.0110 \\
(0.0092)\end{array}$ & $\begin{array}{l}-0.0077 \\
(0.0090)\end{array}$ & $\begin{array}{l}-0.0039 \\
(0.0077)\end{array}$ \\
\hline Individual fixed effects & Yes & Yes & Yes & No \\
\hline $\begin{array}{l}\text { Opponent playing risk averse } \\
\text { strategy }\end{array}$ & Yes & Yes & Yes & Yes \\
\hline Elo points at stake & No & Yes & Yes & Yes \\
\hline Elo differences & No & No & Yes & Yes \\
\hline Observations & 70286 & 70286 & 70286 & 70286 \\
\hline Numb. of players & 9848 & 9848 & 9848 & 9848 \\
\hline
\end{tabular}


Table 8 - OLS estimations regarding the probability of scoring when using an aggressive strategy against female opponents. WOMEN.

Dependent variable: The score achieved in a game

\begin{tabular}{|c|c|c|c|c|}
\hline & (1) & (2) & (3) & $\begin{array}{l}\text { (4) } \\
\text { no fixed } \\
\text { effects }\end{array}$ \\
\hline Playing risky & $\begin{array}{l}-0.1344 \\
(0.1241)\end{array}$ & $\begin{array}{l}-0.1721 \\
(0.1228)\end{array}$ & $\begin{array}{l}-0.1856 \\
(0.1254)\end{array}$ & $\begin{array}{l}-0.1251 \\
(0.1229)\end{array}$ \\
\hline Female opponent & $\begin{array}{c}0.1941 \\
(0.0639)^{* * *}\end{array}$ & $\begin{array}{c}0.0194 \\
(0.0605)\end{array}$ & $\begin{array}{l}-0.0315 \\
(0.0613)\end{array}$ & $\begin{array}{l}-0.0124 \\
(0.0580)\end{array}$ \\
\hline $\begin{array}{l}\text { Play risky against female } \\
\text { opponent }\end{array}$ & $\begin{array}{c}0.1613 \\
(0.1311)\end{array}$ & $\begin{array}{r}0.1492 \\
(0.1290)\end{array}$ & $\begin{array}{c}0.1554 \\
(0.1313)\end{array}$ & $\begin{array}{c}0.0823 \\
(0.1281)\end{array}$ \\
\hline Opponent's attractiveness & $\begin{array}{l}-0.0066 \\
(0.0109)\end{array}$ & $\begin{array}{l}-0.0119 \\
(0.0103)\end{array}$ & $\begin{array}{l}-0.0147 \\
(0.0103)\end{array}$ & $\begin{array}{l}-0.0127 \\
(0.0099)\end{array}$ \\
\hline $\begin{array}{l}\text { Attractiveness and female } \\
\text { opponent }\end{array}$ & $\begin{array}{l}-0.0019 \\
(0.0111)\end{array}$ & $\begin{array}{c}0.0079 \\
(0.0105)\end{array}$ & $\begin{array}{c}0.0112 \\
(0.0106)\end{array}$ & $\begin{array}{c}0.0091 \\
(0.0100)\end{array}$ \\
\hline $\begin{array}{l}\text { Play risky and opponent's } \\
\text { attractiveness }\end{array}$ & $\begin{array}{c}0.0244 \\
(0.0222)\end{array}$ & $\begin{array}{c}0.0312 \\
(0.0217)\end{array}$ & $\begin{array}{c}0.0335 \\
(0.0221)\end{array}$ & $\begin{array}{c}0.0229 \\
(0.0217)\end{array}$ \\
\hline $\begin{array}{l}\text { Play risky against female } \\
\text { opponent and opponent's } \\
\text { attractiveness }\end{array}$ & $\begin{array}{l}-0.0307 \\
(0.0230)\end{array}$ & $\begin{array}{l}-0.0297 \\
(0.0225)\end{array}$ & $\begin{array}{l}-0.0309 \\
(0.0229)\end{array}$ & $\begin{array}{l}-0.0186 \\
(0.0224)\end{array}$ \\
\hline Individual fixed effects & Yes & Yes & Yes & No \\
\hline $\begin{array}{l}\text { Opponent playing risk averse } \\
\text { strategy }\end{array}$ & Yes & Yes & Yes & Yes \\
\hline Elo points at stake & No & Yes & Yes & Yes \\
\hline Elo differences & No & No & Yes & Yes \\
\hline Observations & 30738 & 30738 & 30738 & 30738 \\
\hline Numb. of players & 1259 & 1259 & 1259 & 1259 \\
\hline
\end{tabular}


Figure 3 displays the results when using the second proxy of risk behavior. It shows the estimated coefficients from regressions with different game lengths, i.e. games that ended in 1-20 moves, 1-25 moves, ..., 1-80 moves. ${ }^{18}$ There are not many games ending in a win/loss in fewer than twenty moves. As was explained in the previous section, this follows as the theory maintains the saddle point equilibrium until approximately the $15^{\text {th }}$ to $20^{\text {th }}$ move. The strongest result for men is seen for games ended in less than 35 moves. As we argued, this is due to the fact a player's reaction, when confronting an attractive woman, is likely to occur in the beginning of the game. When the position becomes more complicated it is more likely that the status of the game, and not the players, will influence the choice of strategy. In games ended in less than 35 moves, we find that men, when playing against attractive female opponents, use a more risky strategy compared to when playing against less attractive female opponents. For this game length, the coefficient is significantly different from zero at the 5 percent level of significance. The right chart in Figure 3 shows the corresponding results for women when they play against attractive female opponents. There are no significant differences for any game length. ${ }^{19}$

\footnotetext{
${ }^{18}$ In Appendix Tables A.4 and A.5 we give the results for draws in 1-35 moves.

${ }^{19}$ However, there is a weak growing tendency for women becoming somewhat more risk averse when playing against attractive female opponents the longer the games are.
} 
Figure 3 - Estimated coefficients with dependent variable $=1$ if draw, $=0$ if win/loss for different game lengths in moves. MEN (left) and WOMEN (right).

\section{Attractive female opponent, draw as dependent variable} Coefficient estimates. Upper and lower bound indicating 95\% confidence interval
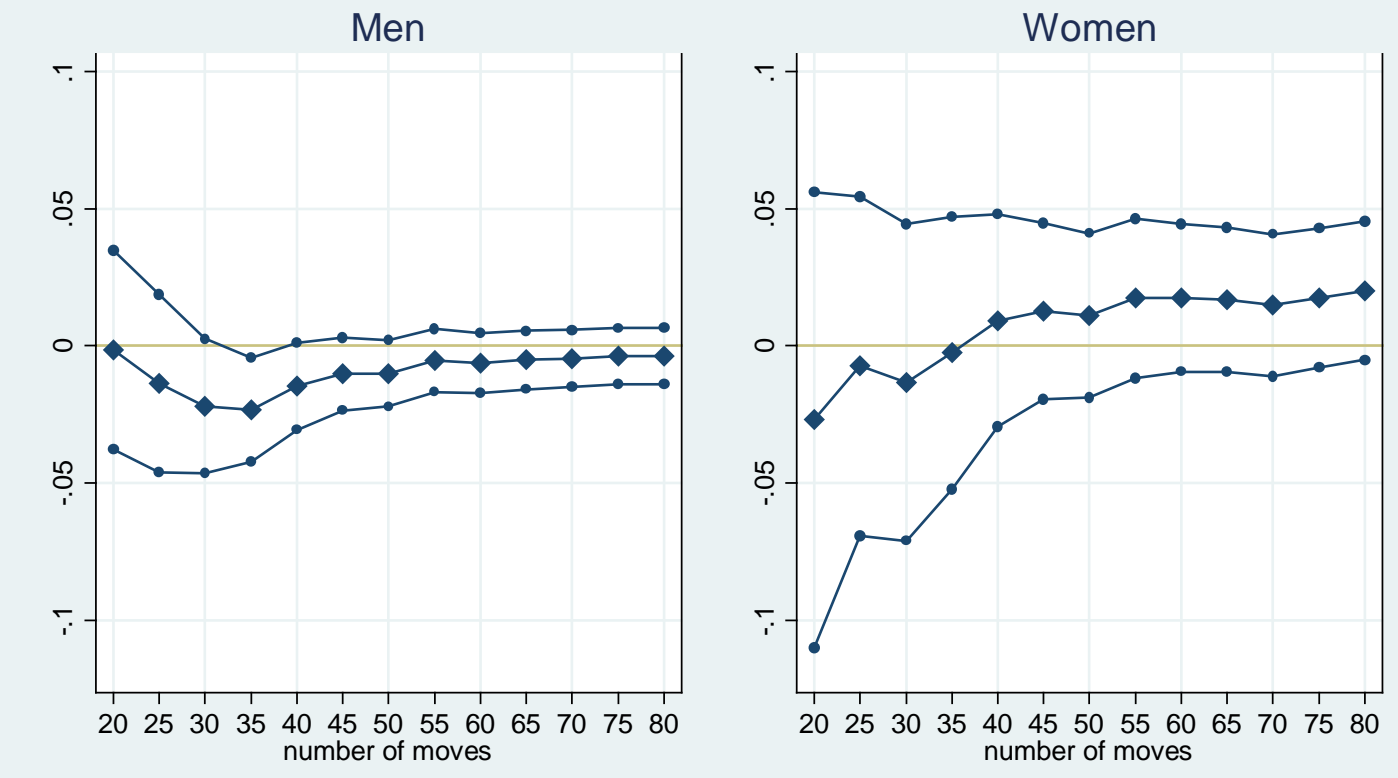

Notes: Estimations controlling for individual fixed effects

Other control variables as in Table 5 and 6 , column(3). Standard errors clustered on individual level

Concluding the results, we find that both approaches used to proxy risk behavior show that men become more risk loving when playing against attractive female opponents. The estimation results based on our first measure show that men choose riskier opening strategies when playing against an attractive female opponent compared to when playing against a less attractive female opponent. The results from the second measure suggest that men have higher preferences for the riskier strategy (playing for a win with the risk of losing rather than accepting a draw) when playing against more attractive female opponents. 


\section{DISCUSSION}

The most robust gender difference in economic behavior has been found for risk preferences, where men typically take more risk than women (Croson and Gneezy 2009, Eckel and Grossman 2008). A number of factors have been suggested for this, including biological variables (e.g. Apicella et al. 2008, Dreber and Hoffman 2010, though see Zethraeus et al. 2009 for evidence not supporting this explanation) as well as cultural variables such as whether girls behave differently depending on if they attend mixed or same sex schools (e.g. Booth and Nolen 2009). These studies typically rely on experimentally elicited risk preferences through gambles, where decisions mainly are made in isolation from other individuals.

In this study we explore to what extent performance and risk taking are affected by the attractiveness of the opponent in chess games. We find that men, but not women, take more risk in chess against more attractive opponents of the opposite gender. Moreover, this elevated risk taking is not beneficial for performance: if anything it is instead costly since the coefficient is rather stable and mostly negative. ${ }^{20}$ The fact that we find similar pattern with both risk measures increases the reliability of the findings. One could argue that time preferences interact with the risk effect. However, the first measure is expected to be positively correlated with time preferences (playing risky may shorten the game through a quick win/loss) whereas the second measure is expected to be negatively correlated with time preferences (accepting a draw now rather than playing for a win should lead to a quicker result). This reduces the likelihood that time preferences are driving the results.

With a high number of observations, and players from a broad range of countries together with a large battery of controls, including fixed effects, these results add to the literature by showing that people, and especially men, may behave differently depending on the degree of physical attractiveness of the counterpart. These effects could certainly be present in various situations in the labor market.

That men and not women change their behavior when playing against an attractive opponent of the opposite gender is in line with some previous results. Wilson and Daly (2004) show that men become more impulsive when viewing an attractive woman compared to a less attractive woman, whereas this effect is not observed for women looking at pictures of men.

\footnotetext{
${ }^{20}$ Van den Bergh et al. (2008) find no negative impact of sexual cues on male performance in a word task and hence no evidence of sexual cues affecting cognitive load. Whether the presence of attractive women affect cognitive load among male chess players in a way that is not related to sexual cues remain to be explored.
} 
Landry et al. (2006) find that for door-to-door charitable fundraising, men respond more to female solicitor attractiveness than women do. Bertrand et al. (2010) find that including an attractive woman in an ad for loans has an equally large effect on men on take up as lowering the interest rate by 25 percent, whereas women do not react to seeing an attractive man or woman. Our results are also related to those of Ariely and Loewenstein (2006) who find that men are more willing to take more sexual risk when sexually aroused. ${ }^{21}$ Sexual risk taking and using a risky strategy in chess are obviously not the same thing, but we speculate that there is an underlying reward circuitry that is activated by both attractive women and sexual cues or explicit sexual images that influences risky behaviors.

We see several lines of promising extensions of this work. An interesting study would be to test whether the impact of an attractive female opponent is the same for a man in a field that is less male-dominated than chess. Another extension would be to see if attractiveness as measured from seeing an individual in person rather than in a photo gives a stronger or weaker behavioral effect than attractiveness ratings measured from photos. There are also other facial characteristics to study, such as facial masculinity, which has been found to correlate with risk taking in a male sample (Apicella et al. 2008). It would also be interesting to compare ratings from head shots with those of full body pictures.

It could turn out that playing a risky strategy against an attractive female player is beneficial for a male player outside of the chess game. To what extent this is the case could be explored by for example combining our data with interviews of the players where after their games they are asked about how impressed they were by their opponent's play and also whether they experienced any flirtation. It would also be interesting to know if men realize they are being riskier when they see an attractive woman; and what effect teaching them about it has on behavior. Finally, we think that another interesting extension would focus on gender composition, attractiveness and risk taking in different domains than chess, such as inside a trading room or in a corporate board room.

\footnotetext{
${ }^{21}$ It would be interesting to see whether sexual arousal also extends to more risk taking in other domains. Moreover, Ariely and Loewenstein (2006) only look at male subjects. It remains to be shown how women’s decision making related to risk taking reacts to sexual arousal.
} 


\section{REFERENCES}

Andreoni, James, and Ragan Petrie. 2008. “Beauty, gender and stereotypes: Evidence from laboratory experiments.” Journal of Economic Psychology, 29(1): 73-93.

Apicella, Coren L., Anna Dreber, Benjamin Campbell, Peter B. Gray, M. Hoffman, and Anthony C. Little. 2008. “Testosterone and Financial Risk Preferences.” Evolution and Human Behavior, 29(6): 384-390.

Ariely, Dan, and George Loewenstein. 2006. “The Heat of the Moment: The Effect of Sexual Arousal on Sexual Decision Making.” Journal of Behavioral Decision Making, 19: 87-98.

Berggren, Niclas, Henrik Jordahl, and Panu Poutvaara 2010. “The Looks of a Winner: Beauty and Electoral Success.” Journal of Public Economics, 94(1-2): 8-15.

Bertrand, Marianne, Dean Karlan, Sendhi Mullainathan, Eldar Shafir, and Jonathan Zinman. 2010. “What’s Advertising Content Worth? Evidence from a Consumer Credit Marketing Field Experiment.” Quarterly Journal of Economics, 125(1): 263-306.

Biddle, Jeff E., and Daniel S. Hamermesh. 1998. "Beauty, Productivity, and Discrimination: Lawyers' Looks and Lucre.” Journal of Labor Economics, 16(1): 172-201.

Buhrmester, Michael D., Tracy Kwang, and Sam D. Gosling (in press). “Amazon’s Mechanical Turk: A New Source of Inexpensive, Yet High-Quality, Data?” Perspectives on Psychological Science.

Croson, Rachel, and Uri Gneezy. 2009. “Gender Differences in Preferences.” Journal of Economic Literature, 47(2): 1-27.

de Firmian, Nick. 2009. Batsford's Modern Chess openings, Batsford, London.

Dreber, Anna, and Moshe Hoffman. 2010. “Biological Basis of Sex Differences in Risk Aversion and Competitiveness.” Mimeo.

Eckel, Catherine C., and Philip J. Grossman. 2008. “Men, Women and Risk Aversion: Experimental Evidence.” In Handbook of Experimental Economics Results, Volume 1, ed. C. Plott and V. Smith, 1061-73. New York Elsevier.

Eckel, Catherine C., and Rick K. Wilson. 2004. “Is trust a risky decision?” Journal of Economic Behavior \& Organization, 55(4): 447-465.

Fletcher, Jason M. 2008. “Beauty vs. brains: Early labor market outcomes of high school graduates.” Economics Letters, 105(3): 321-325.

Gerdes, Christer, and Patrik Gränsmark. 2010. "Strategic Behavior Across Gender: A Comparison of Female and Male Expert Chess Players.” Labour Economics, 17(5): 766-775. Hamermesh, Daniel S., and Jeff E. Biddle. 1994. "Beauty and the Labor Market.” American Economic Review, 84(5): 1174-1194. 
Horton, John, and L.ydia Chilton (in press). "The Labor Economics of Paid Crowdsourcing.” Proceedings of the 11th ACM Conference on Electronic Commerce.

Horton, John, David G. Rand, and Richard J. Zeckhauser. 2010. “The Online Laboratory:

Conducting Experiments in a Real Labor Market.” NBER Working Paper w15691.

Landry, Craig, Andreas Lange, John A. List, Michal Price, and Nicholas Rupp. 2006.

"Towards an Understanding of the Economics of Charity: Evidence from a Field

Experiment.” Quarterly Journal of Economics, 121: 747-782.

Mobius, Markus M., and Tanya S. Rosenblatt. 2006. "Why beauty matters.” American Economic Review, 96(1): 222-235.

Mulford, Matthew, John Orbell, Catherine Shatto, and Jean Stockard. 1998. "Physical Attractiveness, Opportunity, and Success in Everyday Exchange.” American Journal of Sociology, 103(6): 1565-1592.

Paolacci, Gabriele, Jesse Chandler, and Panagiotis G. Ipeirotis. 2010. Judgment and Decision Making. 5(5): 411-419.

Solnick, Sara J., and Maurice E, Schweitzer. 1999. “The Influence of Physical Attractiveness and Gender on Ultimatum Game Decisions.” Organizational Behavior and Human Decision Processes, 79(3): 199-215.

Van den Bergh, Bram, Siegfried Dewitte, and Luk Warlop. 2008. "Bikinis Instigate

Generalized Impatience in Intertemporal Choice.” Journal of Consumer Research, 35: 85-97. Wilson, Margo, and Martin Daly. 2004. “Do Pretty Women Inspire Men to Discount the Future?” Biology Letters, 271: 177-179.

Wilson, Rick K., and Catherine C. Eckel. 2006. “Judging a Book by its Cover: Beauty and Expectations in the Trust Game.” Political Research Quarterly, 59(2): 189-202.

Zethraeus, Niklas, Liljana Kocoska-Maras, Tore Ellingsen, Bo von Schoultz, Angelica Lindén Hirschberg, and Magnus Johannesson. 2009. “A Randomized Trial of the Effect of Estrogen and Testosterone on Economic Behavior.” Proceedings of the National Academy of Sciences, 106(16): 6535-6538.

Internet references

http://www.chessgames.com/perl/explorer?node=32033\&move=2\&moves=e4.c5\&nodes=217 20.32033

Ross, Daniel. “Arpad Elo and the Elo Rating System”:

http://www.chessbase.com/newsdetail.asp?newsid=4326 


\section{APPENDIX}

\section{Rater Characteristics}

The average share of female raters across

questionnaires

\begin{tabular}{|c|c|c|c|}
\hline & Percentiles & Smallest & \\
\hline $1 \%$ & .429 & .429 & \\
\hline $25 \%$ & .551 & & \\
\hline \multicolumn{4}{|l|}{ Media } \\
\hline \multirow{2}{*}{\multicolumn{2}{|c|}{ n . 596}} & Mean value & .595 \\
\hline & & Std. Dev. & .064 \\
\hline $75 \%$ & .64 & Largest & \\
\hline $99 \%$ & .735 & .735 & \\
\hline
\end{tabular}

The average age of the raters across questionnaires

$\begin{array}{rll} & \text { Percentiles } & \text { Smallest } \\ 1 \% & 32.5 & 32.5 \\ 25 \% & 34.196 & \end{array}$

Media

n $35.178 \quad$ Mean value 35.167

Std. Dev. $\quad 1.278$

$\begin{array}{lll}75 \% & 36.087 & \text { Largest } \\ 99 \% & 38.128 & 38.12766\end{array}$

Obs $\quad 61$ questionnaires 
Table A.0 - OLS estimations regarding rater characteristics on attractiveness ratings.

\section{Dependent variable: Attractiveness of MTurk-players}

\begin{tabular}{|c|c|c|c|}
\hline & (1) & (2) & (3) \\
\hline $\begin{array}{l}\text { Share of female raters in } \\
\text { questionnaire }\end{array}$ & $\begin{array}{l}1.3520 \\
(0.9064)\end{array}$ & $\begin{array}{l}1.4047 \\
(0.8820)\end{array}$ & $\begin{array}{l}1.3135 \\
(1.0784)\end{array}$ \\
\hline $\begin{array}{l}\text { Average age of raters in } \\
\text { questionnaire }\end{array}$ & $\begin{array}{l}0.0059 \\
(0.0394)\end{array}$ & $\begin{array}{l}0.0039 \\
(0.0386)\end{array}$ & $\begin{array}{l}0.0038 \\
(0.0387)\end{array}$ \\
\hline Female player & & $\begin{array}{l}0.6068 \\
(0.0733)^{* * *}\end{array}$ & $\begin{array}{l}0.4992 \\
(0.5990)\end{array}$ \\
\hline $\begin{array}{l}\text { Interaction share of female } \\
\text { raters and being female } \\
\text { player }\end{array}$ & & & $\begin{array}{l}0.1812 \\
(1.0095)\end{array}$ \\
\hline Observations & 626 & 626 & 626 \\
\hline R-squared & 0.007 & 0.086 & 0.086 \\
\hline Number of questionnaire & 61 & 61 & 61 \\
\hline
\end{tabular}

Note: Robust standard errors in parentheses * significant at 10\%; ** significant at 5\%; *** significant at $1 \%$ 
Table A.1 - OLS estimations regarding gender differences in playing opening strategies.

\section{Dependent variable:}

\begin{tabular}{|c|c|c|c|c|}
\hline & \multicolumn{2}{|c|}{ risk averse opening strategy } & \multicolumn{2}{|c|}{ risk loving opening strategy } \\
\hline & $(1)$ & (2) & (3) & (4) \\
\hline \multirow[t]{2}{*}{ Elo } & 0.0001 & 0.0001 & -0.0001 & -0.0001 \\
\hline & $(0.0000)^{* * *}$ & $(0.0000) * * *$ & $(0.0000) * * *$ & $(0.0000)^{* * *}$ \\
\hline \multirow[t]{2}{*}{ Female } & 0.0206 & -0.0061 & -0.0253 & -0.0112 \\
\hline & $(0.0096)^{* *}$ & $(0.0158)$ & $(0.0071) * * *$ & $(0.0114)$ \\
\hline \multirow[t]{2}{*}{ Age } & 0.0045 & 0.0047 & -0.0055 & -0.0056 \\
\hline & $(0.0015) * * *$ & $(0.0015) * * *$ & $(0.0011) * * *$ & $(0.0011)^{* * *}$ \\
\hline \multirow[t]{2}{*}{ Age squared } & -0.0000 & -0.0000 & 0.0000 & 0.0000 \\
\hline & $(0.0000)$ & $(0.0000)$ & $(0.0000)^{* * *}$ & $(0.0000)^{* * *}$ \\
\hline \multirow[t]{2}{*}{ Age max 20} & 0.0020 & 0.0024 & -0.0039 & -0.0036 \\
\hline & $(0.0089)$ & $(0.0089)$ & $(0.0072)$ & $(0.0072)$ \\
\hline Log (number of & 0.0032 & 0.0037 & -0.0029 & -0.0032 \\
\hline games played) & $(0.0038)$ & $(0.0037)$ & $(0.0029)$ & $(0.0029)$ \\
\hline North America & & 0.0491 & & 0.0223 \\
\hline female & & $(0.0443)$ & & $(0.0517)$ \\
\hline Latin America & & 0.0007 & & -0.0546 \\
\hline female & & $(0.0369)$ & & $(0.0271)^{* *}$ \\
\hline Nordic countries & & 0.0968 & & -0.0734 \\
\hline female & & $(0.0349) * * *$ & & $(0.0219)^{* * *}$ \\
\hline East Europe & & 0.0294 & & -0.0087 \\
\hline female & & (0.0229) & & $(0.0166)$ \\
\hline Former Soviet Union & & 0.0249 & & -0.0146 \\
\hline female & & $(0.0222)$ & & $(0.0171)$ \\
\hline North Africa/ Middle & & 0.0747 & & -0.0936 \\
\hline East female & & $(0.0529)$ & & $(0.0416)^{* *}$ \\
\hline East Asia & & 0.1028 & & -0.0499 \\
\hline female & & $(0.0373) * * *$ & & $(0.0252)^{* *}$ \\
\hline Africa & & -0.2140 & & -0.0159 \\
\hline female & & $(0.0933)^{* *}$ & & $(0.1216)$ \\
\hline Observations & 101024 & 101024 & 101024 & 101024 \\
\hline
\end{tabular}




\begin{tabular}{l} 
Number of players 1110711107107 \\
\hline Note: Nationality controls are: North America, Latin America, Nordic countries, East Europe, the former \\
Soviet Union, North Africa/Middle-East, East Asia, Africa, with Western Europe as comparison. Year \\
dummies included. Robust standard errors in parentheses, clustered at player level. Sample with 20 or more \\
games played during the period studied. * significant at 10\%; ** significant at 5\%; *** significant at 1\%.
\end{tabular}


In Table A.2 and A.3 below we show estimations for the same sample as in Table 2 and 3, but here the outcome variable is performance in terms of score points. Overall, the coefficient estimates suggest that there is no association between a player's physical attractiveness and his/her performance.

Table A.2 - OLS estimations regarding the impact of physical attractiveness on performance. MEN.

\section{Dependent variable: The score achieved in a game}

(1)

(2)

(3)

(4)

No Elo

control

Attractiveness

$-0.0005$

$-0.0005$

$-0.0028$

$-0.0021$

(0.0030)

(0.0030)

(0.0020)

(0.0018)

Female opponent

0.1305

0.0120

0.0144

$(0.0098)^{* * *}$

(0.0083)

$(0.0083)^{*}$

Individual fixed effects

Indicator opponent playing

No

No

No

No

Yes

No

Yes

No

Yes

No

Elo points at stake

Elo differences

No

No

59004

59004

314

314

Yes

No

Observations

Number of players

59004

59004

Note: Robust standard errors in parentheses, clustered at player level. Other control variables are Elo, age, age squared, age_max_20, log (number of games played), year dummies. Sample not restricted with respect to number of games played. * significant at $10 \%$; ** significant at $5 \%$; *** significant at $1 \%$ 
Table A.3 - OLS estimations regarding the impact of physical attractiveness on performance. WOMEN.

Dependent variable: The score achieved in a game

(1)

(2)

(3)

(4)

$\begin{array}{lcccc} & & & & \text { No Elo } \\ \text { Attractiveness } & \mathbf{0 . 0 0 0 9} & \mathbf{0 . 0 0 0 1} & \mathbf{0 . 0 0 1 0} & \text { control } \\ & \mathbf{( 0 . 0 0 2 5 )} & \mathbf{( 0 . 0 0 2 4 )} & \mathbf{( 0 . 0 0 1 9 )} & \mathbf{( 0 . 0 0 1 8 )} \\ \text { Female opponent } & & 0.0971 & 0.0043 & 0.0065 \\ & & (0.0054)^{* * *} & (0.0044) & \text { (0.0043) } \\ \text { Individual fixed effects } & \text { No } & \text { No } & \text { No } & \text { No } \\ \text { Indicator opponent playing } & \text { No } & \text { Yes } & \text { Yes } & \text { Yes } \\ \text { Solid } & & & & \text { No } \\ \text { Elo points at stake } & \text { No } & \text { No } & \text { Yes } & \text { No } \\ \text { Elo differences } & \text { No } & \text { No } & \text { Yes } & 48234 \\ \text { Observations } & 48234 & 48234 & 48234 & 312 \\ \text { Number of players } & 312 & 312 & 312 & \end{array}$

Note: Robust standard errors in parentheses, clustered at player level. Other control variables are Elo, age, age squared, age_max_20, log (number of games played), year dummies. Sample not restricted with respect to number of games played. * significant at 10\%; ** significant at 5\%; *** significant at $1 \%$ 
Table A.4 - Example estimations with dependent variable 1 if draw in 1-35 moves, 0 if win/loss in 1-35 moves. MEN.

Dependent variable: Draw in 1-35 moves, yes (1) or no (0)
(1)
(2)
(3)
(4)

\begin{tabular}{|c|c|c|c|c|}
\hline & & & & $\begin{array}{l}\text { no fixed } \\
\text { effects }\end{array}$ \\
\hline \multirow[t]{2}{*}{ Female opponent } & -0.0530 & -0.0522 & 0.0949 & 0.0802 \\
\hline & $(0.0110)^{* * *}$ & $(0.0115)^{* * *}$ & $(0.0621)$ & $(0.0452)^{*}$ \\
\hline \multirow[t]{2}{*}{ Attractiveness of opponent } & & -0.0010 & 0.0047 & 0.0018 \\
\hline & & $(0.0043)$ & $(0.0048)$ & $(0.0037)$ \\
\hline Attractiveness and female & & & -0.0232 & -0.0189 \\
\hline opponent & & & $(0.0097)^{* *}$ & $(0.0071)^{* * *}$ \\
\hline Individual fixed effects & Yes & Yes & Yes & No \\
\hline $\begin{array}{l}\text { Opponent playing risk averse } \\
\text { strategy }\end{array}$ & Yes & Yes & Yes & Yes \\
\hline Elo points at stake & Yes & Yes & Yes & Yes \\
\hline Elo differences & Yes & Yes & Yes & Yes \\
\hline Observations & 27558 & 27558 & 27558 & 27558 \\
\hline Number of players & 7126 & 7126 & 7126 & 7126 \\
\hline
\end{tabular}

Note: Robust standard errors in parentheses, clustered at player level. Other control variables are Elo, age, age squared, age_max_20, log (number of games played), year dummies. Sample with 20 or more games played during the period studied. * significant at $10 \%$; ** significant at $5 \%$; *** significant at $1 \%$ 
Table A.5 - Example estimations with dependent variable 1 if draw in 1-35 moves, 0 if win/loss in 1-35 moves. WOMEN.

Dependent variable: Draw in 1-35 moves, yes (1) or no (0)
(1)
(2)
(3)
(4)

no fixed

effects

Female opponent

0.1633
$(0.0261) * * *$

0.1600

0.1752

0.1116

Attractiveness of opponent

$(0.0265)^{* * *} \quad(0.1431)$

(0.1297)

Attractiveness of opponent

0.0041

0.0066

$-0.0017$

(0.0050)

(0.0244)

(0.0219)

Attractiveness and female

$-0.0026$

0.0063

opponent

(0.0252) (0.0226)

Individual fixed effects

Yes

Yes

Yes

No

Opponent playing risk averse

Yes

Yes

Yes

Yes

strategy

Elo points at stake

Yes

Yes

Yes

Yes

Elo differences

Yes

Yes

Yes

Yes

Observations

10095

10095

10095

10095

Number of players

1142

1142

1142

1142

Note: Robust standard errors in parentheses, clustered at player level. Other control variables are Elo, age, age squared, age_max_20, log (number of games played), year dummies. Sample with 20 or more games played during the period studied. * significant at $10 \%$; ** significant at $5 \%$; *** significant at $1 \%$ 